\title{
Genomics and Systems Biology at the "Century of Human Population Genetics" conference
}

\author{
Tatiana V. Tatarinova ${ }^{1,2,3}$, Ancha V. Baranova ${ }^{3,4}$, Anastasia A. Anashkina ${ }^{5}$ and Yuriy L. Orlov ${ }^{6,7,8^{*}}$ \\ From 11th International Young Scientists School "Systems Biology and Bioinformatics" - SBB-2019 \\ Novosibirsk, Russia. 24-28 June 2019
}

This special issue of BMC Genomics presents works in the broad field of genomics as discussed at the "Century of Human Population Genetics" conference in Moscow in May 2019, held at Moscow State University (http:// centenary-popgene.com/). The Conference discussed the current research of gene pools of the world's nations, analysis of ancient DNA, judicial possibilities of human genetics, developemngt of population genetic databases, biobanks, as well as a set of newest additions to the toolbox of genomics technologies. It was an unique event, dedicated to the 100th anniversary of the first human population study performed in 1919 , way before a function of DNA was discovered.

This journal issue also contains materials on human genomics and computational genetics presented at the "Systems Biology and Bioinformatics" (SBB-2019), a School for the Young Scientists held in Novosibirsk, Russia. Since 2008, this traditional school on bioinformatics is organized annually, under joint guidance of the Institute of Cytology and Genetics of the Siberian Branch of the Russian Academy of Sciences and the Novosibirsk State University (http://conf.bionet.nsc.ru/sbb2019/en/) $[1,2]$. Traditionally, the Program Committee selects best conference materials for subsequent publications in BMC Genomics and related journals of BioMed Central [3-6]. The SBB Schools in Novosibirsk are the satellite events for the larger BGRSISB (Bioinformatics of Genome

\footnotetext{
* Correspondence: orlov@d-health.institute

${ }^{6}$ The Digital Health Institute, I.M.Sechenov First Moscow State Medical University (Sechenov University), 119991 Moscow, Russia ${ }^{7}$ Institute of Cytology and Genetics SB RAS, 630090 Novosibirsk, Russia Full list of author information is available at the end of the article
}

Regulation and Structure \Systems Biology) multiconference [1]. At the time of this paper writing, the BGRS $\backslash S B$ 2020 meeting in Novosibirsk just concluded (https:// bgrssb.icgbio.ru/2020/), for the first time its twenty years history in the on-line format.

Therefore, this special issue on genomics and systems biology is accompanied by sister issues in other BMC journals in the fields of genetics, bioinformatics, microbiology, and medical genomics are published as a part of the following series: BMC Bioinformatics, BMC Medical Genomics, BMC Genetics, and BMC Medical Genetics, as well as in BMC Microbiology. In 2018, the conference highlights were organized into the Special Issues with reports from the BGRS $\backslash S B-2018$ Conference and, earlier, from Belyaev Readings-2017 in Novosibirsk [7, 8]. The special issues in BMC Genomics were continued in 2019 $[9,10]$.

We open up this Special Issue by the human population genomics study on genetic determinants for the eye and hair color by Balanovska et al. [11] (This issue).

Predicting the eye and hair color from genotype became an established and widely used tool for both the forensic genetics and for a studies of ancient human populations. Accuracy of these predictions were extensively verified in the West and Central Europeans [12], while the studies in lightly pigmented people from border regions between Europe and Asia, including Caucasus and Ural are lacking. The authors collected 300 samples from across northern Eurasia, phenotyped and genotyped them using HIrisPlex-S markers [13], then estimated the predictive power of these biomarkers in Caucasus/Ural/Siberian populations. As genetic 
ancestries of these populations differ from that of West Europeans, Balanovska and co-authors hypothesized that they allelic spectrum might be also somewhat different. Thus, for all the 300 samples, the authors performed the exome sequencing and performed an enrichment of biomarker set with the 53 genes and intergenic regions associated with the eye/hair color. The association analysis replicated previous finsings concerning some known pigmentation related SNPs but also identified five new markers, with eye color prediction power for North Eurasians comparable with that of two well-known SNPs of this type. Four of these SNPs are located in HERC2 gene. The released dataset may be used for further advancement of population genetics and medical genetics; it describes the exome variation in some undercharacterized indigenous groups, previously studied by SNPs arrays only, but not by the sequencing approach.

The paper by Sandoval and colleagues [14] (this issue) continues topic of human population genetics with an excurse to Latin American and a journey of 'Canaris' people from Ecuador and Peru. According to preHispanic history records, during the conquest and Inka expansion in Ecuador, many Andean families of the Cañar region were been displaced to several places, including Kañaris, a Quechua-speaking community of Peru mountains. The study focused on the genetic footprints of the 'Cañaris' of Cañar compared to other highland populations. The authors analyzed native $\mathrm{Y}$ chromosome haplotypes of local communities-three from Ecuador and seven from Peru - to show that individuals from the Cañar region do not share $\mathrm{Y}$ haplotypes with the Kañaris. Although no close genetic links between the Peruvian Kañaris (including Inkawasi) and Ecuadorian Cañar populations were shown, some congruence with historical records was observed [15].

Suntsova and Buzdin [16] (this issue) review compares human and great apes genomes to reveal genetic features distinguishing us from chimpanzees and making us humans. Even if these features are quantifiable, we still cannot identify with certainty the causative genes of "human identity" [17]. The authors summarize available information about genetic differences between humans and chimpanzees and potential functional impacts of these on differences on molecular, anatomical, physiological, and cognitive features of these species.

The paper by Kirill Danilov and colleagues [18] (this issue) investigates a performance of commonly used genotyping technologies, including Whole Genome (WGS) and Whole Exome Sequencing (WES) [13]. They conclude that WGS genotype callings exhibit higher overall precision within the selected variety of discordantly genotyped variants, a finding relevant to clinical diagnostics of common and rare variants.
The work by Vasilina Akulova et al. [19] (this issue) focuses on a basidiomycete tree fungus (Armillaria borealis) genome. This fungus causes the "white rot" root disease that weakens and even kills woody plants; it is common in Siberia and the Far East [20]. The de novo genome assembly and annotation were performed for the $A$. borealis species for the first time. Functional annotation analysis revealed about 22,000 protein-coding genes and provided data for further comparative analysis with other fungal species. Note that the work by Akulova et al. (this issue) refers to to BMC Plant Biol special issues published in parallel after PlantGen-2019 Conference (http://conf.bionet.nsc.ru/plantgen2019/en/), which continues as a series of special issues at BMC family journals [21].

Through offering schools for young scientists, we aim to support international exchanges and education in the field of computational biology and bioinformatics (https://bgrssb.icgbio.ru/2020/). We invite our worldwide readers to attend our next events - in Novosibirsk and Moscow (https://forum.digital/clinic, http://ngs. med-gen.ru/).

\section{Acknowledgments}

We are grateful to Professors O.P. Balanovsky and G.S. Lebedev for the organization of the "Century of Human Population Genetics" and Digital Medicine conferences in Moscow in 2019 and for compiling materials for the SBB-2019 issues at BioMed Central journals.

This work was supported by a grant from the Ministry of Education and Science of the Russian Federation (project identifier RFMEFI60819X0278).

The guest editors of the special issue are grateful to the conference and school organizing committee members and to all the reviewers who helped in the peer-review and the language editing. We acknowledge Mikhail Ponomarenko and Vadim Efimov (Institute of Cytology and Genetics SB RAS, Novosibirsk, Russia), Hildegard Nikki Hall (University of Edinburgh, UK), Piramanayagam Shanmughavel (Bharatiar University, India), Haiqing Zhao (Columbia University Medical Center, USA), Vitaly Gursky (St.Petersburg Polytech University, Russia), Olga Zolotareva (Bielefeld University, Germany), Elvira Galieva (Novosibirsk State University, Russia), Alexey Kolodkin (University of Luxemburg), Alexander Ratushny and Irina Medvedeva (Bristol Myers Squibb, USA), Olga Arkova (Institute of Gene Biology RAS, Moscow), Larissa Litvinova (I.Kant Baltic Federal University, Kaliningrad), Paul Jones (AIC Inc., USA), Shuan Li (University of Rhode Island, USA), Mengting Liu (University of Southern California, USA), Lydia Manor (AIC Inc., USA), Guohao Wang (NIH, USA), Nina Oparina (Karolinska Institut, Sweden), Stanislav Rybtsov (University of Edinburgh, UK), Anastasia Efimenko (Moscow State University, Russia), Ed Hollox (University of Leicester, USA), Igor Sharakhov (Virginia Tech, USA), Ludmila Zakharenko (Institute of Cytology and Genetics SB RAS, Novosibirsk, Russia), Alexander Konev (NRC «Kurchatov Institute» - PNPI, Gatchina, Russia), Angelica Timofeeva (Moscow State University, Russia), Anatoly Ivashchenko (al-Farabi Kazakh National University, Kazakhstan), Ekaterina Marakasova (US FDA, USA), Chris Tyler-Smith (Sanger Centre, UK), Dmitry Karpov (Institute of Biomedical Chemistry RAS), Nikolai Barlev (Institute of Cytology RAS, St.-Petersburg, Russia), Elena Leberfarb (Novosibirsk State Medical University, Russia), Lyubov Chuvakova (Moscow State University, Russia), Andrei Krivtsov (Dana Farber Cancer Institute, USA), Olga Tarasova (Sechenov University, Moscow, Russia), Nadezhda Antipova (Moscow State University, Russia), Oleg Gusev (RIKEN, Japan), Konstantin Gunbin and Nataly Bondar (Novosibirsk State University, Russia), Hua Zhong (Fred Hutchinson Cancer Research Center, USA), Elena Zaklyazminskaya (Petrovsky Russian Research Centre of Surgery, Russia), Michael Linderman (Icahn School of Medicine at Mount Sinai, USA), Sergei Fedotov (MEPhl, Moscow, Russia), Igor Berezovsky (Bioinformatics Institute, Singapore), Andreas Laner (Medizinisch Genetisches Zentrum, Munich, Germany), Arun Kumar (Shanmugha Arts Science Technology and Research 
Academy, India), Lars Fehren-Schmitz (University of California Santa Cruz, USA), Mikhail Sadovsky (Siberian Federal University, Krasnoyarsk, Russia), Vasily Ramensky (National Research Institute of Preventive Medicine, Moscow, Russia), Patrick Harrison (University College Cork, Ireland).

\section{About this supplement}

This article has been published as part of BMC Genomics Volume 21 Supplement 7, 2020: Selected Topics in "Systems Biology and Bioinformatics" 2019: genomics. The full contents of the supplement are available online at https://bmcgenomics.biomedcentral.com/articles/supplements/volume-21supplement-7.

\section{Authors' contributions}

$\pi, A B$, and $Y O$ are guest editors of the special post-conference issues and Program Committee members of SBB-2019 School. AA is the invited editor and the committee member of the Conference. All the authors read, revised, and approved the final manuscript.

\section{Funding}

Publication of this article was not covered by sponsorship.

\section{Competing interests}

The authors declare that they have no competing interests.

\section{Author details}

'La Verne University, La Verne, CA 91750, USA. ${ }^{2}$ Department of Fundamental Biology and Biotechnology, Siberian Federal University, 660074 Krasnoyarsk, Russia. ${ }^{3}$ George Mason University, Fairfax, VA 22030, USA. ${ }^{4}$ Research Centre for Medical Genetics, 115522 Moscow, Russia. ${ }^{5}$ Engelhardt Institute of Molecular Biology RAS, 119991 Moscow, Russia. ${ }^{6}$ The Digital Health Institute, I.M.Sechenov First Moscow State Medical University (Sechenov University), 119991 Moscow, Russia. Institute of Cytology and Genetics SB RAS, 630090 Novosibirsk, Russia. ${ }^{8}$ Novosibirsk State University, 630090 Novosibirsk, Russia.

\section{Published: 10 September 2020}

\section{References}

1. Baranova AV, Orlov YL. The papers presented at 7th Young Scientists School "Systems Biology and Bioinformatics" (SBB'15): Introductory Note. BMC Genet. 2016;17:S20.

2. Orlov YL, Baranova AV, Hofestaedt R, Kolchanov NA. Computational genomics at BGRSISB-2016: introductory note. BMC Genomics. 2016; 17(Suppl 14):996.

3. Orlov YL, Kolchanov NA, Hofestädt R, Wong L. Editorial - bioinformatics development at the BGRSISB conference series: 10th anniversary. J Bioinforma Comput Biol. 2017:15(2):1702001.

4. Orlov YL, Baranova AV, Markel AL. Computational models in genetics at BGRSISB-2016: introductory note. BMC Genet. 2016;17(Suppl 3):155.

5. Tatarinova TV, Chen M, Orlov YL. Bioinformatics research at BGRS-2018. BMC Bioinformatics. 2019;20(Suppl 1):33.

6. Orlov YL, Baranova AV. Editorial: bioinformatics of genome regulation and systems biology. Front Genet. 2020;11:625.

7. Orlov YL, Baranova AV, Hofestädt R, Kolchanov NA. Genomics at Belyaev conference - 2017. BMC Genomics. 2018;19(Suppl 3):79.

8. Orlov YL, Baranova AV, Tatarinova TV, Kolchanov NA. Genetics at Belyaev conference - 2017: introductory note. BMC Genet. 2017;18(Suppl 1):116.

9. Orlov YL., Kochetov A.V., Li G., Kolchanov N.A. Genomics research at bioinformatics of genome regulation and structure systems biology (BGRSISB) conferences in Novosibirsk. BMC Genomics 2019;20(Suppl 3):322.

10. Orlov YL, Galieva ER, Melerzanov AV. Computer genomics research at the bioinformatics conference series in Novosibirsk. BMC Genomics. 2019; 20(Suppl 7):537.

11. Balanovska E, Lukianova E, Kagazezheva J, Maurer A, Leybova N, Agdzhoyan A, Gorin I, Petrushenko V, Pylev V, Kostryukova E, Balanovsky O. Optimizing the genetic prediction of the eye and hair color for north Eurasian populations. BMC Genomics. 2020;21(Suppl 7). https://doi.org/10.1186/ s12864-020-06923-1.

12. Candille Sl, Absher DM, Beleza S, Bauchet M, McEvoy B, Garrison NA, Li JZ, Myers RM, Barsh GS, Tang H, Shriver MD. Genome-wide association studies of quantitatively measured skin, hair, and eye pigmentation in four European populations. PLoS One. 2012;7(10):e48294.
13. Chaitanya L, Breslin K, Zuñiga S, Wirken L, Pośpiech E, Kukla-Bartoszek M Sijen T. Peter de Knijff, Liu F., Branicki W., Kayser M., Walsh S. the HlrisPlex-S system for eye, hair and skin colour prediction from DNA: introduction and forensic developmental validation. Forensic Sci Int Genet. 2018;35:123-35.

14. Sandoval JR, Lacerda DR, Jota MMS, Robles-Ruiz P, Danos P, Paz-y-Miño C, Wells S, Santos FR, Fujita R. Tracing the genetic history of the 'Canaris' from Ecuador and Peru using uniparental DNA markers. BMC Genomics. 2020; 21(Suppl 7). https://doi.org/10.1186/s12864-020-06834-1.

15. Barbieri C, Barquera R, Arias L, Sandoval JR, Acosta O, Zurita C, et al. The current genomic landscape of Western South America: Andes, Amazonia, and Pacific coast. Mol Biol Evol. 2019:36(12):2698-713.

16. Suntsova MV, Buzdin AA. Differences between human and chimpanzee genomes and their implications in gene expression, protein functions and biochemical properties of the two species. BMC Genomics. 2020;21(Suppl 7). https://doi.org/10.1186/s12864-020-06962-8

17. Dong X, Wang X, Zhang F, Tian W. Genome-wide identification of regulatory sequences undergoing accelerated evolution in the human genome. Mol Biol Evol. 2016;33(10):2565-75.

18. Danilov K.A., Baranova AV, Nikogosov DA, Musienko SV. A comparison of BeadChip and WGS genotyping outputs using partial validation by Sanger sequencing BMC Genomics 2020;21(Suppl 7). https://doi.org/10.1186/ s12864-020-06919-x

19. Akulova VS, Sharov W, Aksyonova Al, Putintseva YA, Oreshkova NV, Feranchuk SI, Kuzmin DA, Pavlov IN, Litovka YA, Krutovsky KV. De novo sequencing, assembly and functional annotation of Armillaria borealis genome BMC Genomics. 2020;21(Suppl 7). https://doi.org/10.1186/s12864020-06964-6.

20. Kolesnikova Al, Putintseva YA, Simonov EP, Biriukov W, Oreshkova NV, Pavlov IN, Sharov W, Kuzmin DA, Anderson JB, Krutovsky KV. Mobile genetic elements explain size variation in the mitochondrial genomes of four closely-related Armillaria species. BMC Genomics. 2019;20(1):351.

21. Orlov YL, Baranova AV, Salina EA. Computational plant bioscience at BGRSISB-2016: introductory note. BMC Plant Biol. 2016;16(Suppl 3):243.

\section{Publisher's Note}

Springer Nature remains neutral with regard to jurisdictional claims in published maps and institutional affiliations.

Ready to submit your research? Choose BMC and benefit from:

- fast, convenient online submission

- thorough peer review by experienced researchers in your field

- rapid publication on acceptance

- support for research data, including large and complex data types

- gold Open Access which fosters wider collaboration and increased citations

- maximum visibility for your research: over $100 \mathrm{M}$ website views per year

At BMC, research is always in progress.

Learn more biomedcentral.com/submission 